\title{
Note of clarification of data in the paper titled X-ray repair cross-complementing group 1 Arg194Trp polymorphism is associated with increased risk of lung cancer in Chinese Han population
}

\author{
Haiyan Yang • Ruo Feng • Haiyu Wang • Yadong Wang
}

Received: 29 January 2015 / Accepted: 2 February 2015 /Published online: 11 February 2015

(C) International Society of Oncology and BioMarkers (ISOBM) 2015

\begin{abstract}
We read with great interest the paper titled "X-ray repair crosscomplementing group 1 Arg194Trp polymorphism is associated with increased risk of lung cancer in Chinese Han population" published in Tumor Biol. 2013, 34: 2611-2615 [1]. Wu et al. performed a meta-analysis to investigate the association between X-ray repair cross-complementing group 1 (XRCC1) Arg194Trp polymorphism and lung cancer risk in Chinese Han population on the basis of 12 case-control studies with 4385 cases and 4545 controls. The authors found that XRCC1 Arg194Trp polymorphism was associated with increased risk of lung cancer in Chinese Han population under three main models (allele contrast model, odds ratio $(\mathrm{OR})=1.12,95 \%$ confidence interval (CI) 1.00-1.26, $P=0.049$; homozygote model, $\mathrm{OR}=1.27,95 \%$ CI $1.09-1.48, P=0.003$; recessive model, $\mathrm{OR}=1.26,95 \%$ CI $1.09-1.46, P=0.003$ ) when all eligible studies were pooled into meta-analysis. It is an interesting study.
\end{abstract}

\section{H. Yang}

Department of Epidemiology, School of Public Health, Zhengzhou University, Zhengzhou 450001, People's Republic of China

\section{R. Feng}

Department of Histology and Embryology, School of Basic Medicine, Zhengzhou University, Zhengzhou 450001, People's

Republic of China

\section{H. Wang $\cdot$ Y. Wang $(\bowtie)$}

Department of Toxicology, Henan Center for Disease Control and Prevention, No. 105 of South Nongye Road, Zhengzhou 450016, People's Republic of China

e-mail: wangyd76@163.com

\section{Y. Wang}

e-mail: wangyd76@yahoo.cn
Nevertheless, a careful examination of the data provided by Wu et al. (Fig. 1 in the original text) [1] revealed two key issues that are worth noticing. Firstly, one overlapping paper [2] was not properly excluded from $\mathrm{Wu}$ et al.'s study [1]. Secondly, four eligible papers [3-6] published before 2013 were not included in Wu et al.'s study [1]. Therefore, the conclusions by Wu et al. [1] are not entirely reliable. In order to obtain a precise estimation of the relationship between XRCC1 Arg194Trp polymorphism and lung cancer risk in Chinese population, a meta-analysis was re-conducted on the basis of a total of 16 studies with 4591 cases and 4899 controls, which may provide comprehensive evidence for the association of XRCC1 Arg194Trp polymorphism with lung cancer risk in Chinese population.

Table 1 listed the general information of selected studies. Table 2 listed the summary odds ratios of the association between XRCC1 Arg194Trp polymorphism and lung cancer risk in Chinese population. Overall, we observed an increased lung cancer risk in Chinese population among subjects carrying XRCC1 $194 \mathrm{Trp} / \mathrm{Trp}$ genotype (OR=1.26, $95 \%$ CI 1.09-1.46) comparing with Arg/ Arg genotype carriers in total population (Fig. 1a). We did not observe any association of Arg/Trp vs. Arg/Arg and Trp/Trp + Arg/Trp vs. Arg/Arg polymorphisms with lung cancer risk in Chinese population $(\mathrm{OR}=1.05,95 \% \mathrm{CI}$ $0.90-1.22$ and $\mathrm{OR}=1.12,95 \%$ CI $0.95-1.31$, respectively) (Fig. 1b, c). In the subgroup analysis by a source of control, we observed an increased risk of XRCC1 194 Trp/Trp vs. Arg/Arg polymorphism for lung cancer in a healthy subject-based study $(\mathrm{OR}=1.34,95 \%$ CI 1.13 1.59) (Table 2); we did not observe any association between XRCC1 Arg194Trp polymorphism and lung cancer risk in additional subgroup analyses (Table 2). Limiting 
Fig. 1 Forest plots for the association between XRCC1 Arg 194Trp polymorphism and lung cancer risk in Chinese population (a Trp/Trp vs. Arg/ Arg, b Arg/Trp vs. Arg/Arg, c Arg/Trp+Trp/Trp vs. Arg/Arg)

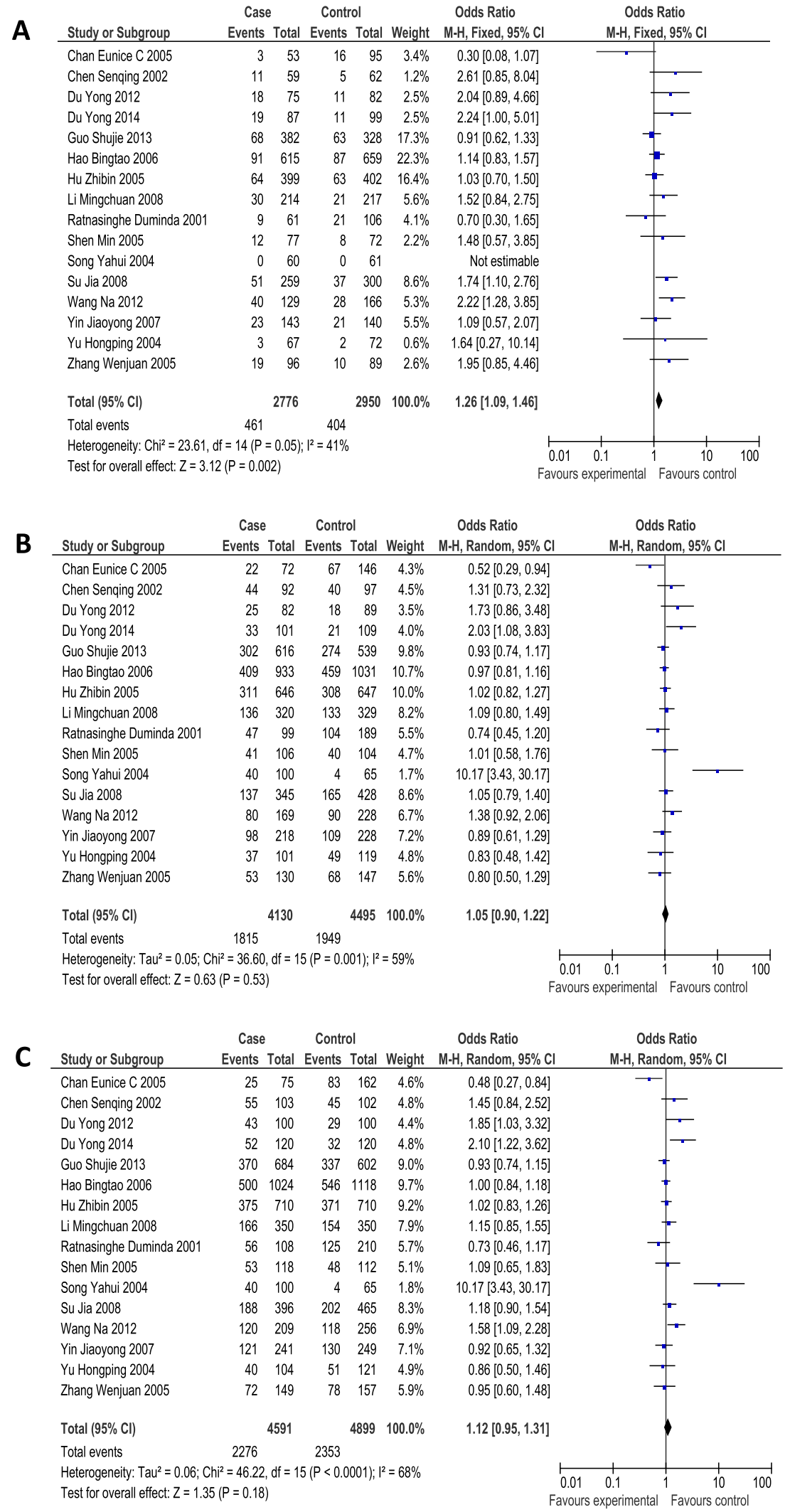

the analysis to the studies with controls in agreement with Hardy-Weinberg equilibrium (HWE), we did not observe any association between XRCC1 Arg194Trp polymorphism and lung cancer risk (Table 2). 
Table 1 Characteristics of selected papers

\begin{tabular}{|c|c|c|c|c|c|c|}
\hline Author & Year & Area & Source of control & Number of case & Number of control & HWE \\
\hline Chan Eunice C [4] & 2005 & Hong Kong & Healthy subjects & 75 & 162 & 0.745951 \\
\hline Chen Senqing [7] & 2002 & Jiangsu & Healthy subjects & 103 & 102 & 0.546278 \\
\hline Du Yong [8] & 2012 & Shanghai & Healthy subjects & 100 & 100 & 0.000012 \\
\hline Du Yong [9] & 2014 & Shanghai & Healthy subjects & 120 & 120 & 0.000009 \\
\hline Guo Shujie [10] & 2013 & Heilongjiang & Hospitalized patients & 684 & 602 & 0.526784 \\
\hline Hao Bingtao [11] & 2006 & Beijing & Healthy subjects & 1024 & 1118 & 0.701669 \\
\hline Hu Zhibin [12] & 2005 & Jiangsu & Healthy subjects & 710 & 710 & 0.556829 \\
\hline Li Mingchuan [13] & 2008 & Liaoning & Hospitalized patients & 350 & 350 & 0.803017 \\
\hline Ratnasinghe Duminda [3] & 2001 & Yunnan & Healthy subjects & 108 & 210 & 0.182984 \\
\hline Shen Min [14] & 2005 & Yunnan & Healthy subjects & 118 & 112 & 0.614295 \\
\hline Song Yahui [5] & 2004 & Jiangsu & Hospitalized patients & 100 & 65 & 0.797994 \\
\hline Su Jia [15] & 2008 & Shanxi & Healthy subjects & 396 & 465 & 0.126621 \\
\hline Wang Na [16] & 2012 & Henan & Healthy subjects & 209 & 256 & 0.027626 \\
\hline Yin Jiaoyong [17] & 2007 & Liaoning & Hospitalized patients & 241 & 249 & 0.570251 \\
\hline Yu Hongping [6] & 2006 & Hubei & Healthy subjects & 104 & 121 & 0.043211 \\
\hline Zhang Wenjuan [18] & 2005 & Henan & Healthy subjects & 149 & 157 & 0.356342 \\
\hline
\end{tabular}

HWE Hardy-Weinberg equilibrium

Publication bias was assessed by funnel plots. The shape of funnel plots seemed to be approximately symmetrical (Fig. 2a-c). The results from Egger's test and Begg's test signified that publication biases might have few effects on this current meta-analysis (Table 2).
Sensitivity analyses were performed to identify the effects of the individual dataset on the summary estimates by sequentially removing each study. The summary effects were not modified when the studies were homogenous for Arg/Trp vs. Arg/Arg and $\operatorname{Trp} / \operatorname{Trp}+\operatorname{Arg} / \operatorname{Trp}$ vs. Arg/Arg polymorphisms among total

Table 2 Summary odds ratios of the relation of XRCC1 Arg194Trp polymorphism to lung cancer risk in Chinese population

\begin{tabular}{|c|c|c|c|c|c|c|c|c|c|c|c|}
\hline \multirow[t]{2}{*}{ Genotype } & \multirow[t]{2}{*}{ Case/control } & \multicolumn{2}{|c|}{ Heterogeneity test } & \multirow[t]{2}{*}{ Summary OR (95% CI) } & \multicolumn{2}{|c|}{ Hypothesis test } & \multirow[t]{2}{*}{ df } & \multicolumn{2}{|c|}{ Begg's test } & \multicolumn{2}{|c|}{ Egger's test } \\
\hline & & $Q$ & $P$ & & $Z$ & $P$ & & $Z$ & $P$ & $t$ & $P$ \\
\hline \multicolumn{12}{|l|}{ Total } \\
\hline Trp/Trp vs. Arg/Arg & $2776 / 2950$ & 23.61 & 0.05 & $1.26(1.09-1.46)$ & 3.12 & 0.002 & 14 & 0.30 & 0.767 & 0.85 & 0.411 \\
\hline Arg/Trp vs. Arg/Arg & $4130 / 4495$ & 36.60 & 0.001 & $1.05(0.90-1.22)$ & 0.63 & 0.53 & 15 & 1.22 & 0.224 & 1.47 & 0.163 \\
\hline $\operatorname{Trp} / \operatorname{Tr} p+\operatorname{Arg} / \operatorname{Trp}$ vs. Arg/Arg & $4591 / 4899$ & 46.22 & $<0.0001$ & $1.12(0.95-1.31)$ & 1.35 & 0.18 & 15 & 1.22 & 0.224 & 1.53 & 0.149 \\
\hline \multicolumn{12}{|l|}{ Stratification by HWE } \\
\hline \multicolumn{12}{|l|}{ Yes } \\
\hline Trp/Trp vs. Arg/Arg & $2418 / 2531$ & 15.25 & 0.12 & $1.15(0.99-1.35)$ & 1.78 & 0.08 & 10 & 0.00 & 1.000 & 0.20 & 0.845 \\
\hline Arg/Trp vs. Arg/Arg & $3677 / 3950$ & 26.38 & 0.006 & $0.99(0.84-1.16)$ & 0.18 & 0.85 & 11 & 0.07 & 1.000 & 0.74 & 0.475 \\
\hline $\operatorname{Trp} / \operatorname{Trp}+\operatorname{Arg} / \operatorname{Trp}$ vs. Arg/Arg & $4058 / 4302$ & 30.50 & 0.001 & $1.03(0.87-1.21)$ & 0.30 & 0.77 & 11 & 0.34 & 0.732 & 0.81 & 0.437 \\
\hline \multicolumn{12}{|l|}{ Stratification by source of control } \\
\hline \multicolumn{12}{|l|}{ Healthy subject-based control } \\
\hline Trp/Trp vs. Arg/Arg & $1997 / 2204$ & 19.59 & 0.05 & $1.34(1.13-1.59)$ & 3.38 & 0.007 & 11 & 0.75 & 0.451 & 0.53 & 0.607 \\
\hline Arg/Trp vs. Arg/Arg & $2876 / 3334$ & 18.10 & 0.08 & $1.01(0.91-1.12)$ & 0.22 & 0.82 & 11 & 0.62 & 0.537 & 0.37 & 0.716 \\
\hline Trp/Trp + Arg/Trp vs. Arg/Arg & $3216 / 3633$ & 27.24 & 0.004 & $1.10(0.92-1.30)$ & 1.06 & 0.29 & 11 & 0.48 & 0.631 & 0.47 & 0.646 \\
\hline \multicolumn{12}{|l|}{ Hospitalized patient-based control } \\
\hline Trp/Trp vs. Arg/Arg & $799 / 746$ & 2.05 & 0.36 & $1.06(0.80-1.42)$ & 0.43 & 0.67 & 2 & 0.00 & 1.000 & 1.19 & 0.444 \\
\hline Arg/Trp vs. Arg/Arg & $1254 / 1161$ & 18.66 & 0.0003 & $1.29(0.80-2.07)$ & 1.04 & 0.30 & 3 & 1.02 & 0.308 & 2.87 & 0.103 \\
\hline Trp/Trp+Arg/Trp vs. Arg/Arg & $1375 / 1266$ & 18.97 & 0.0003 & $1.30(0.82-2.06)$ & 1.13 & 0.26 & 3 & 1.02 & 0.308 & 3.11 & 0.090 \\
\hline
\end{tabular}

HWE, Hardy-Weinberg equilibrium 

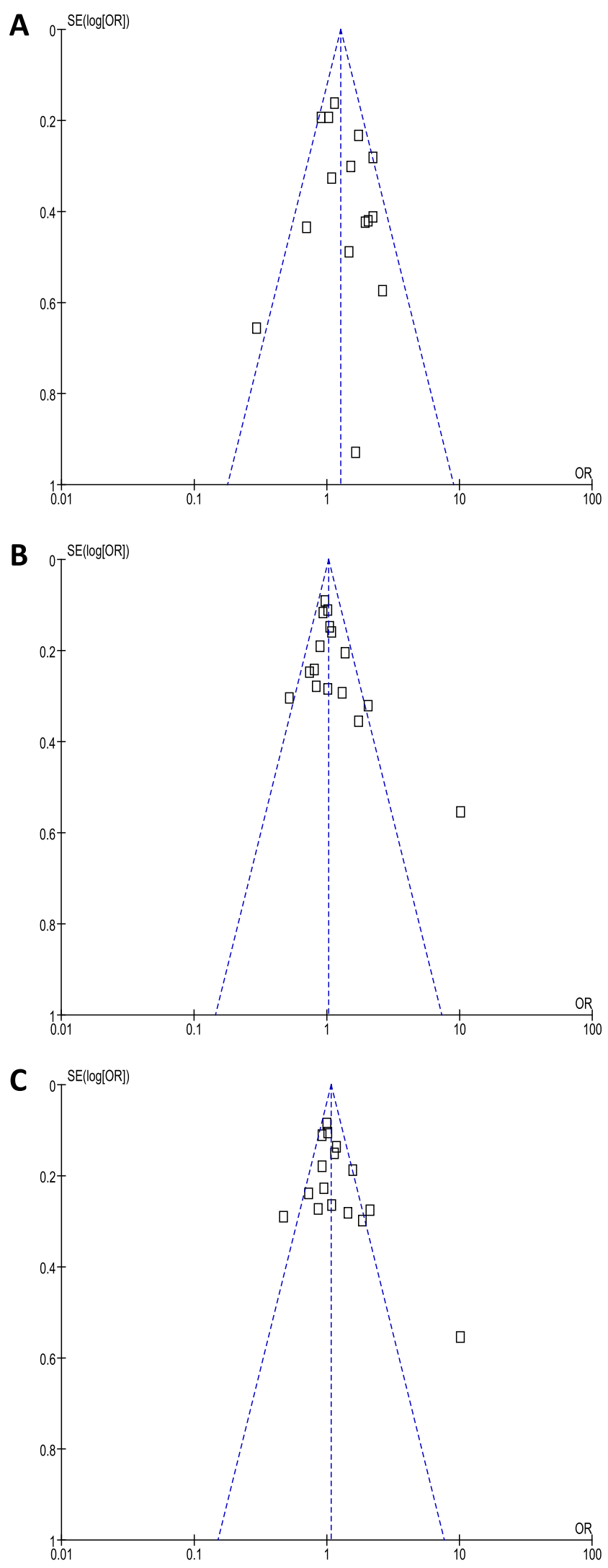

Fig. 2 Funnel plots of the association between XRCC1 Arg194Trp polymorphism and lung cancer risk in Chinese population in the heterozygous model (a Trp/Trp vs. Arg/Arg, b Arg/Trp vs. Arg/Arg, c Arg/Trp+Trp/Trp vs. Arg/Arg)

population by deleting Song et al.'s study and Chan et al.'s study (data not shown).

In conclusion, the findings of the study by $\mathrm{Wu}$ et al. [1] should be interpreted with caution. To reach a definitive conclusion, well-designed studies with large sample size are still required to assess the association of XRCC1 Arg194Trp polymorphism with lung cancer risk in Chinese population. We hope that this remark will contribute to more accurate elaboration and substantiation of the results provided by Wu et al. [1].

Conflicts of interest None

\section{References}

1. Wu T, Xu YH, Ye XL. X-ray repair cross-complementing group 1 Arg194Trp polymorphism is associated with increased risk of lung cancer in Chinese Han population. Tumour Biol. 2013;34:2611-5.

2. Yin J, Vogel U, Ma Y, Qi R, Wang H. Association of DNA repair gene XRCC1 and lung cancer susceptibility among nonsmoking Chinese women. Cancer Genet Cytogenet. 2009;188:26-31.

3. Ratnasinghe D, Yao SX, Tangrea JA, Qiao YL, Andersen MR, Barrett MJ, et al. Polymorphisms of the DNA repair gene XRCC1 and lung cancer risk. Cancer Epidemiol Biomarkers Prev. 2001;10: 119-23.

4. Chan EC, Lam SY, Fu KH, Kwong YL. Polymorphisms of the GSTM1, GSTP1, MPO, XRCC1, and NQO1 genes in Chinese patients with non-small cell lung cancers: relationship with aberrant promoter methylation of the CDKN2A and RARB genes. Cancer Genet Cytogenet. 2005;162:10-20.

5. Song Y, Yin L, Pu Y, Liang G, Cui H. Relationship between polymorphisms of DNA repair gene XRCC1 and susceptibility to lung cancer in Nanjing population. J Labour Med. 2004;21:18-21.

6. Yu H, Zeng X, Chou X, Xu S, Shi L, Zhang X, et al. Polymorphism in the DNA repair gene XRCC1 and susceptibility to human lung cancer. J Guangxi Med Univ. 2006;23:355-8.

7. Chen S, Tang D, Xue K, Xu L, Ma G, Hsu Y, et al. DNA repair gene XRCC1 and XPD polymorphisms and risk of lung cancer in a Chinese population. Carcinogenesis. 2002;23:1321-5.

8. Du Y, Chu DJ, Shi JM, Fan W. The relationship between lung cancer and genetic polymorphism of XRCC1. J Clin Intern Med. 2012;29:346-8.

9. Du Y, He Y, Mei Z, Qian L, Shi J, Jie Z. Association between genetic polymorphisms in XPD and XRCC1 genes and risks of non-small cell lung cancer in East Chinese Han population. Clin Respir J. 2014. doi:10.1111/crj.12218.

10. Guo S, Li X, Gao M, Li Y, Song B, Niu W. The relationship between $\mathrm{XRCC} 1$ and XRCC3 gene polymorphisms and lung cancer risk in northeastern Chinese. PLoS One. 2013;8:e56213.

11. Hao B, Miao X, Li Y, Zhang X, Sun T, Liang G, et al. A novel T-77C polymorphism in DNA repair gene XRCC1 contributes to diminished promoter activity and increased risk of non-small cell lung cancer. Oncogene. 2006;25:3613-20.

12. Hu Z, Ma H, Lu D, Zhou J, Chen Y, Xu L, et al. A promoter polymorphism $(-77 \mathrm{~T}>\mathrm{C})$ of DNA repair gene $\mathrm{XRCC1}$ is associated with risk of lung cancer in relation to tobacco smoking. Pharmacogenet Genomics. 2005; 15:457-63. 
13. Li M, Yin Z, Guan P, Li X, Cui Z, Zhang J, et al. XRCC1 polymorphisms, cooking oil fume and lung cancer in Chinese women nonsmokers. Lung Cancer. 2008;62:145-51.

14. Shen M, Berndt SI, Rothman N, Mumford JL, He X, Yeager M, et al. Polymorphisms in the DNA base excision repair genes APEX1 and XRCC1 and lung cancer risk in Xuan Wei. China Anticancer Res. 2005;25:537-42.

15. Su J, Niu RG, Han XY, Shi JP, Liu L, Li JW, et al. Polymorphisms of DNA repair gene XRCC1 codon 194 and its susceptibility to lung cancer. Fudan Univ J Med Sci. 2008;35:348-52.
16. Wang N, Wu Y, Zhou X. Association between genetic polymorphism of metabolizing enzymes and DNA repairing enzymes and the susceptibility of lung cancer in Henan population. Wei Sheng Yan Jiu. 2012;41:251-6.

17. Yin J, Vogel U, Ma Y, Qi R, Sun Z, Wang H. The DNA repair gene $\mathrm{XRCC} 1$ and genetic susceptibility of lung cancer in a northeastern Chinese population. Lung Cancer. 2007;56: 153-60.

18. Zhang W, Wu Y, Wu Y. Study on polymorphism of XRCC1 and susceptibility to lung cancer. China Public Health. 2005;5:561-3. 